\title{
Paraquat pretreatment alters antioxidant enzyme activity and protects chloroplast ultrastructure in heat-stressed cucumber leaves
}

\author{
Y. GAO, Y.-K. GUO, A.-H. DAI, W.-J. SUN and J.-G. BAI* \\ State Key Laboratory of Crop Biology, College of Life Sciences, Shandong Agricultural University, \\ Tai'an, Shandong 271018, P.R. China
}

\begin{abstract}
Cucumis sativus $\mathrm{L}$. seedlings were pretreated $1 \mathrm{~h}$ with $10 \mu \mathrm{M}$ paraquat (PQ) and then were subjected to normal $\left(25 / 18{ }^{\circ} \mathrm{C}\right)$ or elevated $\left(42 / 38{ }^{\circ} \mathrm{C}\right)$ temperature to investigate whether PQ can protect plants against heat stress. Heat stress inhibited fresh and dry masses of the second leaf, root dry mass and shoot fresh mass. In leaves, the stress disintegrated membranes of $84.97 \%$ chloroplasts and elevated contents of malondialdehyde, superoxide radical and hydrogen peroxide. In contrast, PQ pretreatment altered antioxidant activities in leaves, even after PQ was rinsed off before seedlings were exposed to different temperatures. Under heat stress, PQ pretreatment improved plant growth, decreased percentage of abnormal chloroplasts $(53.03 \%$ ) and reduced contents of malonaldehyde, superoxide radical and hydrogen peroxide due to increased activities of antioxidant enzymes such as superoxide dismutase, catalase, guaiacol peroxidase, glutathione peroxidase, ascorbate peroxidase, monodehydroascorbate reductase, dehydroascorbate reductase and glutathione reductase.
\end{abstract}

Additional key words: antioxidant enzymes, Cucumis sativus, malondialdehyde, reactive oxygen species.

Heat stress damages photosynthetic apparatus and depresses plant growth (Ogweno et al. 2008). Stresses cause accumulation of reactive oxygen species (ROS) such as superoxide anion and hydrogen peroxide, resulting in cell damage. To control ROS, plants evolve antioxidant enzymes (Wahid et al. 2007).

Paraquat (PQ), a bipyridylium herbicide, acts in irradiated chloroplasts by generating $\mathrm{O}_{2}{ }^{--}$(Ananieva et al. 2004). However, it also stimulates antioxidant enzymes in leaves (Ekmekci and Terzioglu 2005), and thereby PQ pretreatment increased drought resistance of cucumbers (Liu et al. 2009). We hypothesize that PQ pretreatment at a certain concentration induces moderate stress and influences antioxidant activities in leaves. Then rinsing off PQ can eliminate PQ-induced stress, however, the increased antioxidant activities can protect chloroplasts and improve plant growth under subsequent heat stress. To date, no reports show that PQ pretreatment alleviates heat stress induced damage. In this study, PQ-pretreated cucumbers were exposed to day/night temperature of $42 / 38^{\circ} \mathrm{C}$ as in Ma et al. (1998) to examine whether PQ could protect plants from heat stress and if this was associated with antioxidant activity regulation and chloroplast ultrastructural changes.

Each cucumber (Cucumis sativus L. cv. Chunguang No. 2) seedling was grown in one $10-\mathrm{cm}$ pot filled with sand at $25{ }^{\circ} \mathrm{C}$ and $12-\mathrm{h}$ photoperiod $\left(600 \mu \mathrm{mol} \mathrm{m} \mathrm{m}^{-2} \mathrm{~s}^{-1}\right)$ and watered twice per day with Hoagland nutrient solution (Gao et al. 2010). At the two-leaf stage, 72 selected cucumber seedlings were randomly allocated into nine groups. The second leaves of one group were immediately harvested, four groups were watered with Hoagland nutrient solution containing $10 \mu \mathrm{M} P Q$, while the other four groups were watered with Hoagland nutrient solution alone. Seedlings were then kept at a weak irradiance $\left(100 \mu \mathrm{mol} \mathrm{m} \mathrm{m}^{-2}\right)$ for $1 \mathrm{~h}$ to enable PQ to

Received 9 June 2010, accepted 15 December 2010.

Abbreviations: APX - ascorbate peroxidase; CAT - catalase; DHAR - dehydroascorbate reductase; GPX - guaiacol peroxidase; GR - glutathione reductase; GSH-Px - glutathione peroxidase; MDA - malondialdehyde; MDHAR - monodehydroascorbate reductase; PQ - paraquat; ROS - reactive oxygen species; SOD - superoxide dismutase.

* Corresponding author; fax: (+86) 538 8242217, e-mail: baijg@sdau.edu.cn 
induce moderate stress. Subsequently, the second leaves were harvested from one group of PQ-pretreated and one group of PQ-untreated seedlings, and other plants were rinsed 12 times with Hoagland nutrient solution to remove $\mathrm{PQ}$. Since $\mathrm{PQ}$ acts only under irradiance, the rinsed plantlets were kept in darkness for $24 \mathrm{~h}$ to eliminate the PQ stress. Then the second leaves were harvested from one group of PQ-pretreated and one group of PQ-untreated seedlings. Meanwhile, two separate groups of $\mathrm{PQ}$-pretreated seedlings were exposed to $25 / 18{ }^{\circ} \mathrm{C}$ (PQ pretreatment) and $42 / 38{ }^{\circ} \mathrm{C}$ (PQ + heat treatment) in growth chambers. Two respective PQ-untreated groups were treated as above; the group at $25 / 18{ }^{\circ} \mathrm{C}$ was named 'control' and the group at $42 / 38^{\circ} \mathrm{C}$ was named 'heat treatment'. The latter four groups were all exposed to $75 \%$ air humidity and 12-h photoperiod (300 $\left.\mu \mathrm{mol} \mathrm{m} \mathrm{m}^{-2} \mathrm{~s}^{-1}\right)$ to enable seedlings to grow well in growth chambers, and the second leaves were harvested after keeping in heat stress for $72 \mathrm{~h}$ when the leaf edges dried in the heat treatment group. Three sets of plants grown at different time were used for each treatment.

Transmission electron microscopy of leaves was performed according to Helliot et al. (2003) with the modifications of $\mathrm{Xu}$ et al. (2008). Malondialdehyde (MDA) content was measured at 450, 532 and $600 \mathrm{~nm}$ according to Dhindsa et al. (1981) with the modifications of Zhang et al. (2005). $\mathrm{O}_{2}^{--}$formation rate and $\mathrm{H}_{2} \mathrm{O}_{2}$ content were determined according to Elstner and Heupel (1976) and Bernt and Bergmeyer (1974), respectively. The activity of superoxide dismutase (SOD) was assayed according to Hwang et al. (1999), the activity of catalase (CAT) according to Pereira et al. (2002), of guaiacol peroxidase (GPX) according to Ramiro et al. (2006), of glutathione peroxidase (GSH-Px) according to Xue et al. (2001), of ascorbate peroxidase (APX) according to Zhu et al. (2004), of monodehydroascorbate reductase (MDHAR) according to Hoque et al. (2007), of dehydroascorbate reductase (DHAR) according to Doulis et al. (1997) and glutathione reductase (GR) according to Foyer and Halliwell (1976). Protein contents of each enzyme extract were determined according to Bradford (1976). Data were collected from three replicates and were expressed as means \pm standard deviations. Differences were analyzed with one-way ANOVA and the least significant difference (LSD). $P$ values $<0.05$ were considered to be significant.

In this study, heat treatment significantly decreased root dry mass, shoot fresh mass, and fresh and dry masses of the second leaf in comparison to control (Table 1). Wahid et al. (2007) also found inhibition of plant growth by heat. At $1 \mathrm{~h}$ after PQ pretreatment under irradiance or at $25 \mathrm{~h}$ after rinsing off PQ for $24 \mathrm{~h}$, the growth parameters were not significantly different between PQ-pretreated and untreated plants, suggesting that PQ at a certain concentration does not influence plant growth at normal temperature. However, the growth parameters were significantly elevated in the PQ + heat treatment group when compared to the heat treatment group at $97 \mathrm{~h}$, indicating that PQ improves plant growth under heat stress.

We found in the heat treatment group that $84.97 \pm$ $2.53 \%$ of chloroplasts were abnormal and swollen to varying degrees and had the disorganized non-parallel lamellae, whereas the control had normal chloroplasts and thylakoids (Fig. 1). Xu et al. (2006) also observed heat damages to chloroplasts and their thylakoids. Under heat stress, trehalose pretreatment protects chloroplast thylakoid membranes (Luo et al. 2010). Similarly, in the PQ + heat treatment group of our study, chloroplast thylakoids were well organized and only $53.03 \pm 3.39 \%$ of chloroplasts had abnormal shape, which was significantly lower than in the heat treatment group, indicating that PQ protected chloroplast ultrastructure in heat-stressed leaves. The altered ultrastructure is consistent with plant growth difference.

MDA contents in leaves were highest in heat treatment. Gao et al. (2010) also found that heat stress damaged cell membranes and increased MDA content. Also PQ treatment significantly increased MDA content in wild wheat (Ekmekci and Terzioglu 2005). Similarly, MDA content at $1 \mathrm{~h}$ was significantly higher in the PQ-pretreated seedlings than in control, suggesting that $1 \mathrm{~h}$ of PQ pretreatment under irradiance caused membrane lipid peroxidation. At 25 or $97 \mathrm{~h}$, since PQ had been rinsed off for 24 or $96 \mathrm{~h}$ respectively, MDA contents in leaves were not significantly different between the PQ pretreatment and control groups. In contrast, MDA content in the PQ + heat treatment group was significantly lower than in the heat treatment group. So PQ decreased MDA content in heat-stressed leaves, which is similar to the report that salicylic acid alleviated heat stress-induced lipid peroxidation (Asthir et al. 2009). The decreased MDA in PQ-pretreated stressed seedlings is consistent with altered plant growth and chloroplast ultrastructure, suggesting that PQ reduced membrane lipid peroxidation and thereby alleviated heat-induced damage to chloroplast ultrastructure and so improved seedling growth.

The contents of $\mathrm{O}_{2}{ }^{-}$and $\mathrm{H}_{2} \mathrm{O}_{2}$ were highest in heat treatment. Zhang et al. (2010) also found heat-induced ROS formation. PQ-induced $\mathrm{O}_{2}{ }^{-}$in irradiated chloroplasts can be dismutated into $\mathrm{H}_{2} \mathrm{O}_{2}$ by $\mathrm{SOD}$ (Ananieva et al. 2004). Therefore, after PQ pretreatment for $1 \mathrm{~h}$ at irradiance of $100 \mu \mathrm{mol} \mathrm{m} \mathrm{m}^{-2} \mathrm{~s}^{-1}, \mathrm{O}_{2}^{--}$and $\mathrm{H}_{2} \mathrm{O}_{2}$ contents were significantly higher than in control. However at $25 \mathrm{~h}$, the contents of two ROS in PQ-pretreated leaves were not significantly different from those in control, because PQ had been rinsed off for $24 \mathrm{~h}$ and the PQ-induced stress was eliminated. PQ pretreatment can reduce $\mathrm{O}_{2}{ }^{--}$and $\mathrm{H}_{2} \mathrm{O}_{2}$ contents under drought stress (Liu et al. 2009). Similarly, $\mathrm{O}_{2}{ }^{--}$and $\mathrm{H}_{2} \mathrm{O}_{2}$ contents were significantly decreased in leaves of the PQ + heat treatment group compared to the heat treatment group. So PQ decreased ROS formation under heat stress, 
which is consistent with the altered MDA content.

Some antioxidant enzymes alleviate ROS in chloroplasts (Gao et al. 2010, Liu et al. 2010). Therefore, we measured activities of eight enzymes to study the relationship between chloroplast ultrastructural changes and antioxidant activities.
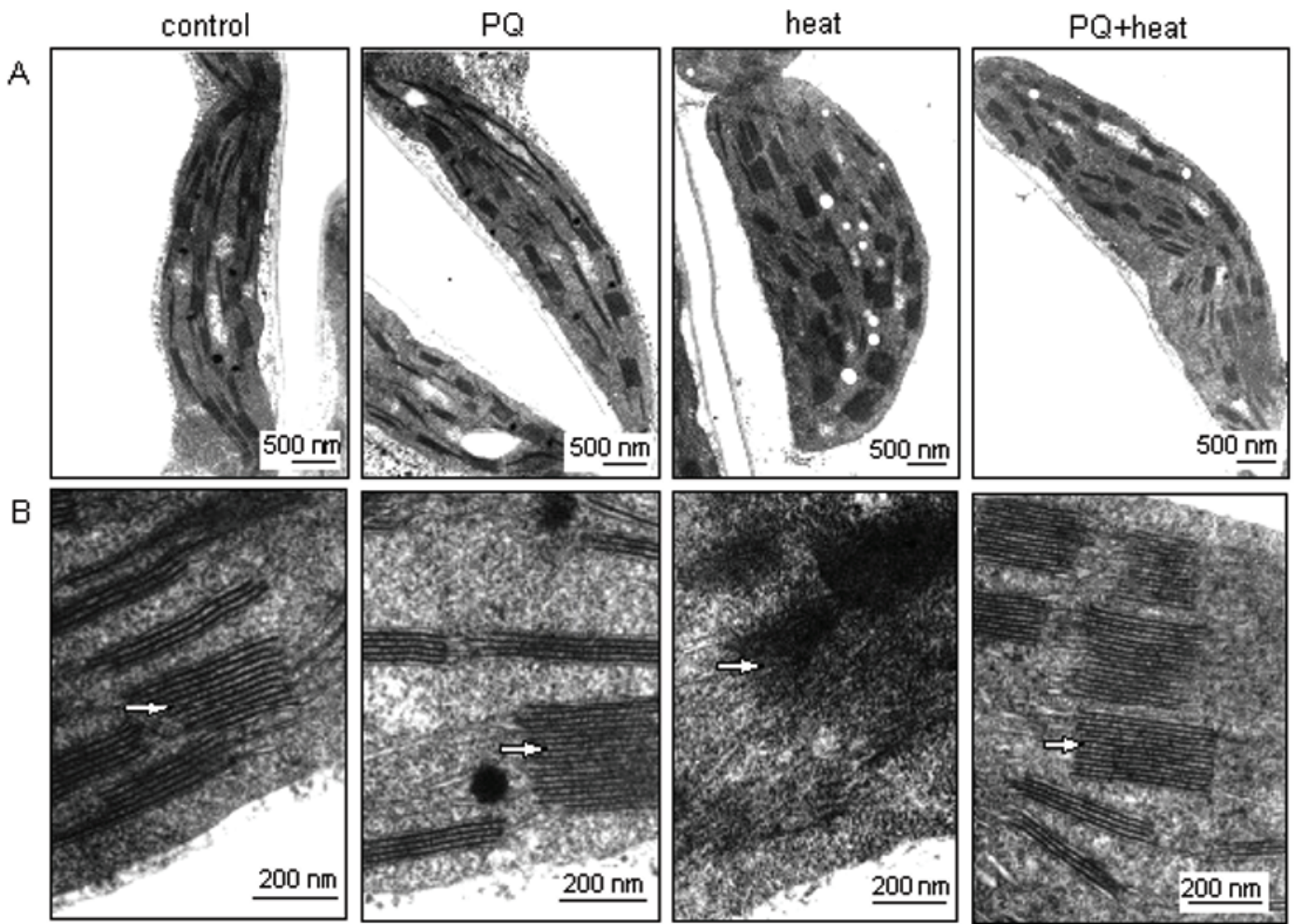

Fig. 1. Chloroplasts $(A)$ and chloroplast thylakoids $(B)$ in the first palisade parenchyma layer of PQ pretreated cucumber seedlings at 97 h. Control $-25 / 18^{\circ} \mathrm{C}, \mathrm{PQ}-\mathrm{PQ}$ pretreatment and then $25 / 18^{\circ} \mathrm{C}$, heat $-42 / 38^{\circ} \mathrm{C}$, PQ + heat - PQ pretreatment and then $42 / 38^{\circ} \mathrm{C}$. The differences among the four treatments are marked with white arrows.

Table 1. Changes in plant growth, contents of MDA, $\mathrm{O}_{2}{ }^{--}, \mathrm{H}_{2} \mathrm{O}_{2}$ and activities of antioxidant enzymes in the second leaves after PQ pretreatment and heat stress. Control $-25 / 18{ }^{\circ} \mathrm{C}$; PQ - PQ pretreatment and then $25 / 18{ }^{\circ} \mathrm{C}$; heat $-42 / 38{ }^{\circ} \mathrm{C}$; PQ + heat - PQ pretreatment and then $42 / 38{ }^{\circ} \mathrm{C}$. Each value represents the mean of at least three replicates \pm SD. Different letters indicate statistically significant differences between treatments at $P<0.05$.

\begin{tabular}{|c|c|c|c|c|c|}
\hline Parameters & $\begin{array}{l}0 \mathrm{~h} \\
\text { control }\end{array}$ & $\begin{array}{l}97 \mathrm{~h} \\
\text { control }\end{array}$ & PQ & heat & PQ + heat \\
\hline Leaf fresh mass [mg] & $628.37 \pm 109.49 \mathrm{bc}$ & $891.53 \pm 29.86 \mathrm{a}$ & $879.03 \pm 52.56 \mathrm{a}$ & $478.80 \pm 16.13 \mathrm{c}$ & $717.67 \pm 24.65 b$ \\
\hline Leaf dry mass $[\mathrm{mg}]$ & $61.79 \pm 5.97 \mathrm{c}$ & $91.27 \pm 6.25 \mathrm{ab}$ & $91.60 \pm 1.19 \mathrm{a}$ & $61.83 \pm 5.72 \mathrm{c}$ & $80.27 \pm 3.20 \mathrm{~b}$ \\
\hline Root dry mass $[\mathrm{mg}]$ & $26.37 \pm 2.99 b$ & $36.37 \pm 0.91 \mathrm{a}$ & $38.27 \pm 1.91 \mathrm{a}$ & $29.93 \pm 0.93 b$ & $39.60 \pm 2.05 \mathrm{a}$ \\
\hline Shoot fresh mass [g] & $1.71 \pm 0.07 \mathrm{bc}$ & $1.97 \pm 0.05 \mathrm{a}$ & $1.92 \pm 0.04 \mathrm{ab}$ & $1.57 \pm 0.06 \mathrm{c}$ & $1.91 \pm 0.04 \mathrm{ab}$ \\
\hline $\operatorname{MDA}\left[\mathrm{nmol} \mathrm{g}^{-1}\right.$ (f.m.) $]$ & $6.59 \pm 0.07 \mathrm{bc}$ & $6.40 \pm 0.06 \mathrm{~cd}$ & $6.28 \pm 0.03 \mathrm{~d}$ & $7.60 \pm 0.14 \mathrm{a}$ & $6.67 \pm 0.07 \mathrm{~b}$ \\
\hline $\mathrm{O}_{2} \cdot-\left[\mathrm{nmol} \mathrm{g}^{-1}\right.$ (f.m) $]$ & $4.10 \pm 0.10 \mathrm{~b}$ & $4.16 \pm 0.09 b$ & $3.90 \pm 0.06 \mathrm{bc}$ & $4.72 \pm 0.09 \mathrm{a}$ & $3.97 \pm 0.09 \mathrm{bc}$ \\
\hline $\mathrm{H}_{2} \mathrm{O}_{2}\left[\mathrm{nmol} \mathrm{g}{ }^{-1}\right.$ (f.m.) $]$ & $189.81 \pm 3.86 \mathrm{~d}$ & $167.52 \pm 2.23 \mathrm{e}$ & $171.98 \pm 4.46 \mathrm{e}$ & $285.65 \pm 2.23 \mathrm{a}$ & $243.30 \pm 7.72 b$ \\
\hline $\mathrm{SOD}\left[\mathrm{U} \mathrm{mg}^{-1}\right.$ (protein) $]$ & $58.91 \pm 0.94 \mathrm{a}$ & $45.25 \pm 0.39 \mathrm{c}$ & $46.82 \pm 0.34 \mathrm{~b}$ & $41.31 \pm 0.43 \mathrm{e}$ & $43.19 \pm 0.47 \mathrm{~d}$ \\
\hline CAT $\left[\right.$ nmol mg ${ }^{-1}$ (protein) $\left.\min ^{-1}\right]$ & $67.47 \pm 0.51 \mathrm{e}$ & $92.17 \pm 1.16 \mathrm{c}$ & $125.40 \pm 4.82 \mathrm{ab}$ & $120.36 \pm 3.19 b$ & $134.13 \pm 2.62 \mathrm{a}$ \\
\hline GPX $\left[\mathrm{nmol} \mathrm{mg}^{-1}\right.$ (protein) $\left.\mathrm{min}^{-1}\right]$ & $55.44 \pm 0.00 \mathrm{e}$ & $121.88 \pm 5.86 \mathrm{c}$ & $156.11 \pm 3.39 b$ & $161.89 \pm 6.23 b$ & $186.80 \pm 6.44 \mathrm{a}$ \\
\hline GSH-Px [nmol mg ${ }^{-1}$ (protein) $\mathrm{min}^{-1}$ ] & $275.84 \pm 7.68 \mathrm{~d}$ & $218.29 \pm 12.36 \mathrm{ef}$ & $352.37 \pm 10.25 \mathrm{c}$ & $479.67 \pm 17.09 b$ & $544.76 \pm 11.76 \mathrm{a}$ \\
\hline APX $\left[\mathrm{nmol} \mathrm{mg}^{-1}\right.$ (protein) $\left.\mathrm{min}^{-1}\right]$ & $701.80 \pm 12.67 \mathrm{f}$ & $736.04 \pm 10.17 \mathrm{ef}$ & $794.85 \pm 9.34 \mathrm{~cd}$ & $972.24 \pm 13.09 b$ & $1059.93 \pm 1.93 \mathrm{a}$ \\
\hline MDHAR [nmol mg ${ }^{-1}$ (protein) $\left.\mathrm{min}^{-1}\right]$ & $114.37 \pm 5.26 \mathrm{~cd}$ & $134.00 \pm 5.83 \mathrm{c}$ & $158.66 \pm 5.42 b$ & $161.62 \pm 1.79 b$ & $218.00 \pm 2.44 \mathrm{a}$ \\
\hline DHAR $\left[\mathrm{nmol} \mathrm{mg} \mathrm{m}^{-1}\right.$ (protein) $\left.\mathrm{min}^{-1}\right]$ & $185.76 \pm 3.56 \mathrm{e}$ & $192.35 \pm 0.81 \mathrm{e}$ & $226.23 \pm 1.22 \mathrm{c}$ & $345.89 \pm 3.57 \mathrm{~b}$ & $357.82 \pm 1.93 \mathrm{a}$ \\
\hline $\mathrm{GR}\left[\mathrm{nmol} \mathrm{mg}{ }^{-1}\right.$ (protein) $\left.\mathrm{min}^{-1}\right]$ & $2.19 \pm 0.06 \mathrm{~g}$ & $2.88 \pm 0.08 \mathrm{~d}$ & $3.71 \pm 0.13 \mathrm{c}$ & $4.70 \pm 0.03 b$ & $5.12 \pm 0.10 \mathrm{a}$ \\
\hline
\end{tabular}


Heat stress decreases SOD activity (Asthir et al. 2009) but increases GPX, CAT (Chaitanya et al. 2002) and APX (Hu et al. 2010) activities. Similarly, compared to control, our heat treatment obviously decreased SOD activity and significantly increased the activities of CAT, GPX, GSH-Px, APX, MDHAR, DHAR and GR. However, the heat treatment induced highest $\mathrm{O}_{2}^{-{ }^{-}}$and $\mathrm{H}_{2} \mathrm{O}_{2}$ contents, indicating that generation of ROS exceeds the capacity of antioxidant enzymes. Compared to control, PQ-pretreated leaves at $1 \mathrm{~h}$ had the significantly increased CAT activity. Liu et al. (2009) also found that PQ activates CAT. In the PQ-pretreated seedlings at $25 \mathrm{~h}$, activities of both CAT and APX were significantly higher than in control, showing that the effects of PQ pretreatment existed after PQ removal. Similarly, at $97 \mathrm{~h}$, activities of SOD, GPX, GSH-Px, MDHAR, DHAR and GR were elevated. All 8 enzymes were significantly increased in the PQ pretreatment group compared to the control group, indicating that effects of $P Q$ on antioxidant enzymes still existed at $97 \mathrm{~h}$. Thus, when PQ-pretreated seedlings were transferred to heat conditions, activities of SOD, CAT, GPX, GSH-Px, APX, MDHAR, DHAR and GR in leaves of the $P Q+$ heat treatment group were more increased compared to heat treatment alone. This is similar to a report that $\mathrm{H}_{2} \mathrm{O}_{2}$ pretreatment enhances the activities of SOD, CAT, GPX, GSH-Px, APX, MDHAR,
DHAR and GR in cucumber leaves under osmotic stress (Liu et al. 2010), and we conclude that PQ increases antioxidant enzyme activities under heat stress. However, the irradiance at 1,25 , and $97 \mathrm{~h}$ was different, which might be another reason that antioxidant activities in the PQ pretreatment group varied during treatment time. However, all treatment groups at $97 \mathrm{~h}$ had the same experimental conditions except for temperature, and therefore the different antioxidant activities would be due to heat stress and PQ pretreatment. The higher activities of SOD, CAT, GPX, GSH-Px, APX, MDHAR, DHAR and GR in PQ-pretreated stressed leaves coincide with decreased $\mathrm{O}_{2}{ }^{-}, \mathrm{H}_{2} \mathrm{O}_{2}$ and MDA contents. Consistently with the ultrastructure and plant growth results, PQ increases cucumber's ability to eliminate $\mathrm{O}_{2}{ }^{--}$and $\mathrm{H}_{2} \mathrm{O}_{2}$ via antioxidant enzymes. Therefore $\mathrm{PQ}$ application decreases lipid peroxidation, protects chloroplast ultrastructure in heat-stressed leaves and improves plant growth.

In conclusion, heat stress in cucumber leaves adversely affects growth, chloroplast shape and ultrastructure, due to increased contents of MDA, $\mathrm{H}_{2} \mathrm{O}_{2}$ and $\mathrm{O}_{2}{ }^{-}$. PQ pretreatment increases antioxidant enzyme activities and thereby eliminates accumulation of MDA, $\mathrm{H}_{2} \mathrm{O}_{2}$ and $\mathrm{O}_{2}{ }^{-}$under heat stress, thus protecting chloroplast ultrastructure and improving plant growth.

\section{References}

Ananieva, E.A., Christov, K.N., Popova, L.P.: Exogenous treatment with salicylic acid leads to increased antioxidant capacity in leaves of barley plants exposed to paraquat. - J. Plant Physiol. 161: 319-328, 2004.

Asthir, B., Kaur, S., Mann, S.K.: Effect of salicylic and abscisic acid administered through detached tillers on antioxidant system in developing wheat grains under heat stress. - Acta Physiol. Plant. 31: 1091-1096, 2009.

Bernt, E., Bergmeyer, H.U.: Inorganic peroxides. - In: Bergmeyer, H.U. (ed.): Methods of Enzymatic Analysis. Pp. 2246-2248. Academic Press, New York 1974.

Bradford, M.M.: A rapid and sensitive method for the quantitation of microgram quantities of protein utilizing the principle of protein-dye binding. - Anal. Biochem. 72: 248254, 1976.

Chaitanya, K.V., Sundar, D., Masilamani, S., Ramachandra Reddy, A.: Variation in heat stress-induced antioxidant enzyme activities among three mulberry cultivars. - Plant Growth Regul. 36: 175-180, 2002.

Dhindsa, R.S., Plumb-Dhindsa, P., Thorpe, T.A.: Leaf senescence: correlated with increased levels of membrane permeability and lipid peroxidation and decreased levels of superoxide dismutase and catalase. - J. exp. Bot. 32: 93-101, 1981.

Doulis, A.G., Debian, N., Kingston-Smith, A.H., Foyer, C.H.: Differential localization of antioxidants in maize leaves. Plant Physiol. 114: 1031-1037, 1997.

Ekmekci, Y., Terzioglu, S.: Effects of oxidative stress induced by paraquat on wild and cultivated wheats. - Pestic.
Biochem. Physiol. 83: 69-81, 2005.

Elstner, E.F., Heupel, A.: Inhibition of nitrite formation from bydroxylam-moniumchloride: a simple assay for superoxide dismutase. - Anal. Biochem. 70: 616-620, 1976.

Foyer, C.H., Halliwell, B.: The presence of glutathione and glutathione reductase in chloroplasts: a proposed role in ascorbic acid metabolism. - Planta 133: 21-25, 1976.

Gao, Y., Guo, Y.K., Lin, S.H., Fang, Y.Y., Bai, J.G.: Hydrogen peroxide pretreatment alters the activity of antioxidant enzymes and protects chloroplast ultrastructure in heatstressed cucumber leaves. - Sci. Hort. 126: 20-26, 2010.

Helliot, B., Swennen, R., Poumay, Y., Frison, E., Lepoivre, P., Panis, B.: Ultrastructural changes associated with cryopreservation of banana (Musa spp.) highly proliferating meristems. - Plant Cell Rep. 21: 690-698, 2003.

Hoque, M.A., Banu, M.N.A., Okuma, E., Amako, K., Nakamura, Y., Shimoishi, Y., Murata, Y.: Exogenous proline and glycinebetaine increase $\mathrm{NaCl}$-induced ascorbate-glutathione cycle enzyme activities, and proline improves salt tolerance more than glycinebetaine in tobacco Bright Yellow-2 suspension-cultured cells. - J. Plant Physiol. 164: 1457-1468, 2007.

Hu, W.H., Xiao, Y.A., Zeng, J.J., Hu, X.H.: Photosynthesis, respiration and antioxidant enzymes in pepper leaves under drought and heat stresses. - Biol. Plant. 54: 761-765, 2010.

Hwang, S.Y., Lin, H.W., Chern, R.H., Lo, H.F., Li, L.: Reduced susceptibility to water logging together with high-light stress is related to increases in superoxide dismutase and catalase activities in sweet potato. - Plant Growth Regul. 27: 
167-172, 1999.

Liu, Z.J., Guo, Y.K., Bai, J.G.: Exogenous hydrogen peroxide changes antioxidant enzyme activities and protects ultrastructure in leaves of two cucumber ecotypes under osmotic stress. - J. Plant Growth Regul. 29: 171-183, 2010.

Liu, Z.J., Zhang, X.L., Bai, J.G., Suo, B.X., Xu, P.L., Wang, L.: Exogenous paraquat changes antioxidant enzyme activities and lipid peroxidation in drought-stressed cucumber leaves. - Sci. Hort. 121: 138-143, 2009.

Luo, Y., Li, F., Wang, G.P., Yang, X.H., Wang, W.: Exogenouslysupplied trehalose protects thylakoid membranes of winter wheat from heat-induced damage. - Biol. Plant. 54: 495$501,2010$.

Ma, D., Pang, J., Li, S., Huo, Z.: Effects of temperature stress acclimation on some physiological characters in leaves of cucumber seedlings. - Acta hort. sin. 25: 350-355, 1998.

Ogweno, J.O., Song, X.S., Shi, K., Hu, W.H., Mao, W.H., Zhou, Y.H., Yu, J.Q., Nogués, S.: Brassinosteroids alleviate heat-induced inhibition of photosynthesis by increasing carboxylation efficiency and enhancing antioxidant systems in Lycopersicon esculentum. - J. Plant Growth Regul. 27: 49-57, 2008.

Pereira, G.J.G., Molina, S.M.G., Lea, P.J., Azevedo, R.A.: Activity of antioxidant enzymes in response to cadmium in Crotalaria juncea. - Plant Soil 239: 123-132, 2002.

Ramiro, D.A., Guerreiro-Filho, O., Mazzafera, P.: Phenol contents, oxidase activities, and the resistance of coffee to the leaf miner Leucoptera coffeella. - J. chem. Ecol. 32: 1977-1988, 2006.

Wahid, A., Gelani, S., Ashraf, M., Foolad, M.R.: Heat tolerance in plants: an overview. - Environ. exp. Bot. 61: 199-223,
2007.

Xu, P.L., Guo, Y.K., Bai, J.G., Shang, L., Wang, X.J.: Effects of long-term chilling on ultrastructure and antioxidant activity in leaves of two cucumber cultivars under low light. Physiol. Plant. 132: 467-478, 2008.

Xu, S., Li, J.L., Zhang, X.Q., Wei, H., Cui, L.J.: Effects of heat acclimation pretreatment on changes of membrane lipid peroxidation, antioxidant metabolites, and ultrastructure of chloroplasts in two cool-season turfgrass species under heat stress. - Environ. exp. Bot. 56: 274-285, 2006.

Xue, T., Hartikainen, H., Piironen, V.: Antioxidative and growth-promoting effect of selenium on senescing lettuce. Plant Soil 237: 55-61, 2001.

Yun, B.W., Huh, G.H., Kwon, S.Y., Lee, H.S., Jo, J.K., Kwak, S.S.: Antioxidant enzymes in Nicotiana cells containing an Ipomoea peroxidase gene. - Phytochemistry 48: 1287-1290, 1998.

Zhang, J.H., Huang, W.D., Liu, Y.P., Pan, Q.H.: Effects of temperature acclimation pretreatment on the ultrastructure of mesophyll cells in young grape plants (Vitis vinifera L. cv. Jingxiu) under cross-temperature stresses. - J. Integr. Plant Biol. 47: 959-970, 2005.

Zhang, X.Y., Hu, C.G., Yao, J.L.: Tetraploidization of diploid Dioscorea results in activation of the antioxidant defense system and increased heat tolerance. - J. Plant Physiol. 167: 88-94, 2010.

Zhu, Z., Wei, G., Li, J., Qian, Q., Yu, J.: Silicon alleviates salt stress and increases antioxidant enzymes activity in leaves of salt-stressed cucumber (Cucumis sativus L.). - Plant Sci. 167: 527-533, 2004. 